\title{
Modifying composition of plastering mortar for the purpose of enhancing fire resistance of building structures by means of silicate additives
}

\author{
Nikita Levashov ${ }^{1}$, Marina Akulova ${ }^{2}$ and Yulia Sokolova ${ }^{3}$ \\ ${ }^{1}$ Military unit 65451, the Ministry for Defence of the Russian Federation, Baturina street, 12, Ivanovo, \\ 153000 , Russia \\ ${ }^{2}$ Ivanovo State Polytechnic University, the Department of buildings materials science, special \\ processes and technological complexes, Sheremetevskij prospekt, 21, Ivanovo, 153000, Russia \\ ${ }^{3}$ Moscow State University of Civil Engineering, Yaroslavskoe shosse, 26, Moscow, 129337, Russia
}

\begin{abstract}
The present paper deals with modifying composition of plastering mortar for the purpose of enhancing fire resistance of building structures by means of silicate additives. Interaction of soluble water glass with cement binder elongates the initiation of setting time and reduces the time of final setting that could be explained by the opposed action of each component. One of the components facilitates the increase in the mobility of the mortar while the other, as opposed, is fastening rapidly. The optimum choice of the mixing ratio in the mortar would enhance both physical-mechanical and thermal properties.
\end{abstract}

\section{Introduction}

Binders on the base of soluble water glass are proved to be very efficient for high-temperature-resisting concretes and mortars [1]. The active structuring and control of operating abilities of these materials by means of change of various technological parameters such as the content of soluble water glass in the mortar mix, type and quantity of inhibiting additives and floured reinforcing fillers, particle-size analysis, type and the nature of coarse aggregate, the modes and methods of mortar mix compaction, etc., enabled to develop the reliable technology for producing high-temperature-resisting concretes and mortars ensuring the manufacture of materials with given properties $[2,3,7,8,9]$.

It's worth mentioning that soluble water glass has high adhesive properties relative to all the materials applied in refractory industry; its adhesive capacity is $3 \ldots 5$ times as high as of cements.

One of the reasons determining efficiency of application of refractory mortars and their reliability is residual strength after heating. The feature distinguishing refractory mortars

\footnotetext{
Corresponding author: akylova@yandex.ru
} 
from standard ones is that for the former the main criteria of their reliability is relatively low initial (control) strength while retaining sufficiently high strength throughout all the temperature range of service life of building materials [10].

Hardening of phosphate binders and adhesives on the base of soluble water glass is distinct due to the fact that hydrated new growths do not play the main part in structure formation of cement stone. Along with that, while heating such materials, dehydration is observed but it takes place at significantly low level than for the materials based on phosphate compounding $[11,12,13]$.

Summarizing all the above mentioned, the authors have made a conclusion that from the point of strength retention and enhanced reliability, the adhesives on the base of phosphate compounding or soluble water glass could be referred as the most efficient binders for refractory mortars.

Soluble water class is not a scarce material and has relatively low cost, thus it could be seen as an optimal binder for high-temperature-resisting concretes. From the perspective of thermal resistance, the maximum effect could be achieved when applying an adhesive on the base of soluble water glass in combination with a filler of similar chemical composition.

The composition of refractory plastering based on soluble water glass binder is intended to have an inhibiting additive on the base of available raw materials.

In order to extend the setting up time of the mortar designated for refractory plastering, the inhibiting additives are introduced in its composition. There substances could initiate the chemical processes resulting in inhibition of the processes of hydration and hydrolysis of clinker minerals that lead to retarded rate of setting up of clinker cements mixed with water.

\section{Materials and methods}

For carrying out the investigation designed for development of refractory binder and a concrete on its base the most widely applied adhesive is soluble water glass. In the research the authors applied sodium silicate solute manufactured on the chemical plants with the density of $1.4 \mathrm{~g} / \mathrm{cm}^{3}$ and silicate module equal to 2.8-3.0.

One of the values determining the efficiency of application and reliability of refractory mortars is their retention strength after heating.

While introducing soluble water glass into the plastering mortar the setting up time and the mobility of the mortar are reduced dramatically. In order to enhance these properties it's proposed to mix the additives inhibiting setting up time, i.e. hardening retarders $[14,15,16]$.

One of the most efficient methods of improving crack resistance of mortar stone is introduction of reinforcing fibers in its composition such as ragstone, glass-fiber, etc. In this case the growth of crack resistance is usually related to the increase of tensile strength.

Here should be mentioned the following advantages of fiber application in the mortar:

- the increase of textural integrity and modeling ability;

- the increase of resistance to freezing and thawing;

- enhancement of water retention of fresh mortar;

- $\quad$ augmentation of resistance to abrasion;

- improvement of high temperature resistance.

In the present research the impact of mineral wool fiber of Rockwool trademark has been investigated. The specific features of fibers are the following: length $-3-5 \mathrm{~mm}$, thickness- 50 mkm. 


\section{Results}

The main property of mineral wool which is distinct from other heat insulating materials is in its noncombustibility in combination with high heat- and sound-insulating ability, resistance to thermal deformations, poor moisture absorption, chemical and biological resistance, sustainability and easy installation.

In compliance with the standards of fire safety, mineral wool products are related to the class of non-combustible materials. Moreover, they prevent flame propagation and could be applied for fire-proof insulation and fire retardation. Also the mineral wool articles could be used at extremely high temperatures provided that they are not exposed to mechanical loads causing their displacement after destruction of the present binding component $[17,18,19$, 20].

Mineral wool insulating materials are characterized by high resistance to chemical attack. Moreover, mineral wool presents itself a chemically-passive medium and does not cause corrosion of contacting metals. Heat insulating and mechanical properties of mineral wool products remain stable at the initial level for decades.

The bars with the dimensions $4 \times 4 \times 16 \mathrm{~cm}$ have been made from the developed mortar compositions for determining ultimate compressive strength and tensile strength at 28 days. The specimens have been kept at room temperature-humidity conditions. The test results are presented in the table 1.

Table 1. Physical and mechanical properties of mortar composition with reinforcing fibers.

\begin{tabular}{|l|c|c|}
\hline \multirow{2}{*}{ Type of composition } & Ultimate strength, MPa \\
\cline { 2 - 3 } & tensile & compressive \\
\hline Composition without fibers & 2 & 19.7 \\
\hline Composition with the content of fibers $0.5 \% *$ & 2.2 & 20.1 \\
\hline Composition with the content of fibers $1.75 \%$ & 2.4 & 19.8 \\
\hline Composition with the content of fibers 3\% & 2 & 14 \\
\hline
\end{tabular}

*fibers percentage content of dry mass stock (cement + sand)

In accordance to the obtained data the authors have come to the following conclusion: tensile strength is somewhat higher for the reinforced compositions proving that for material fracture, complementary energy is required for fiber breaking and pulling. However, this effect could be achieved at the certain fiber-to-cement ration. The further increase in the percentage content of mineral wool fibers would lead to reduction of mortar strength.

In order to define water uptake of mortar there have been made cube-shaped specimens with the edge $3 \mathrm{~cm}$, subsequently dried until they reach fixed mass at the temperature of $105-110^{\circ} \mathrm{C}$. The test results are given in the table 2 . 
Table 2. Water saturation factor for mortar compositions with reinforcing fibers.

\begin{tabular}{|l|c|}
\hline \multicolumn{1}{|c|}{ Type of composition } & Water saturation factor, $\%$ \\
\hline Composition without fibers & 13 \\
\hline Composition with the content of fibers $0.5 \% *$ & 16 \\
\hline Composition with the content of fibers $1.75 \%$ & 20 \\
\hline Composition with the content of fibers $3 \%$ & . \\
\hline
\end{tabular}

*fibers percentage content of dry mass stock (cement + sand)

As seen from the presented data, water saturation factor is higher for the reinforced mortar compositions proving that the number of pores in mortar composition is increasing.

In order to estimate thermal conductivity of the tested mortars, plate-shaped specimens with the dimensions 250x250x40mm have been made. The specimen is being dried until it reaches the fixed mass indicated in the assessment reference for material or product. The specimen is considered to be dried till fixed mass if its mass loss does not exceed $0.1 \%$ after next drying during $30 \mathrm{~min}$. When drying is completed, the specimen mass and density have been determined, and then the specimen has been immediately placed in the device for defining heat transfer resistance. Having completed the tests, the specimen mass was determined and the obtained results were analyzed. The test results are presented in the table 3 and figure 1 .

Table 3. Thermal conductivity of tested mortar compositions with reinforcing fibers.

\begin{tabular}{|l|c|c|c|c|c|}
\hline \multirow{2}{*}{$\begin{array}{l}\text { Type of } \\
\text { composition }\end{array}$} & Hot & Cold & $\begin{array}{c}\text { Specific heat flow, } \\
\frac{W t}{m^{2}}\end{array}$ & $\begin{array}{c}\text { Heat transfer } \\
\text { resistance, } \\
m^{2} x^{0} C / W t\end{array}$ & $\begin{array}{c}\text { Coefficient } \\
\text { of heat } \\
\text { conductivity } \\
\lambda_{0}, \frac{W t}{m^{0} C}\end{array}$ \\
\cline { 2 - 3 } $\begin{array}{l}\text { Composition } \\
\text { without fibers }\end{array}$ & 28.19 & 24.57 & 99.63 & 0,036 & 1.110 \\
\hline $\begin{array}{l}\text { Composition with } \\
\text { the content of } \\
\text { fibers 0.5\%* }\end{array}$ & 28.32 & 24.62 & 104.30 & 0,0355 & 1.058 \\
\hline $\begin{array}{l}\text { Composition with } \\
\text { the content of } \\
\text { fibers 1.75\% }\end{array}$ & 28.54 & 25.11 & 90.68 & 0,038 & 0.954 \\
\hline $\begin{array}{l}\text { Composition with } \\
\text { the content of } \\
\text { fibers 3\% }\end{array}$ & 28.27 & 23.84 & 89.53 & 0,050 & 0.778 \\
\hline
\end{tabular}

*fibers percentage content of dry mass stock (cement + sand) 


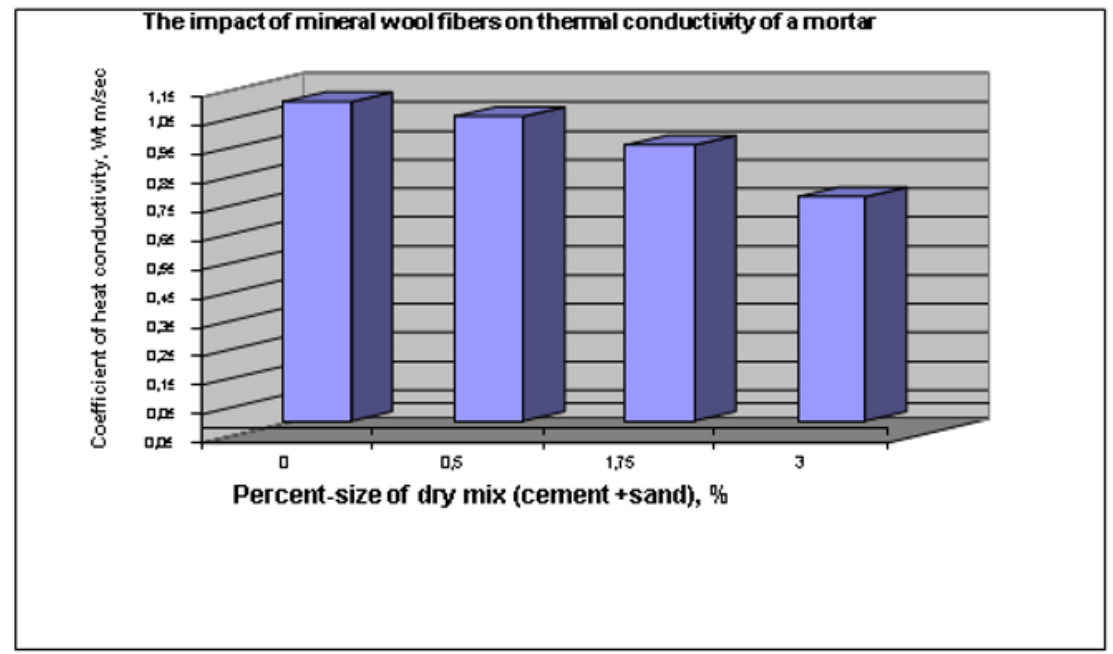

Fig.1. The impact of the content of mineral wool fibers on heat conductivity of plaster morta.

The analysis of the given data has shown that heat conductivity of the specimen reinforced with fibers is higher that could be explained by the increase in the number of pores in mortar and reducing its density. According to the tests results [4], the recommended content of soluble water glass is in the range $5-20 \%$ of water volume. As soluble water glass is instantly setting with cement, the application of inhibiting additives is of practical importance.

For the purpose of investigation the influence of soluble water glass on thermal characteristics of mortars, there has been carried out the comparative analysis of specimen without additives (clear specimen) and the specimens containing soluble water glass. The thermal resistance tests for refractory mortars have been done in compliance with the All-Union Standard GOST 20910.

Water to cement proportion of the mixture was assumed as 0.5 . The table 4 presents the influence of introduction of soluble water glass on thermal resistance of plaster mortar containing Portland cement of the grade 400 and high-silica sand. As seen from the given data, the specimen of composition 2 has exhibited the most prominent thermal resistant properties. Further increase of soluble water glass volume is not efficient due to instant mortar setting up.

Table 4. The influence of soluble water glass mass content on thermal resistance of plaster mortar.

\begin{tabular}{|l|c|c|c|c|}
\hline \multirow{2}{*}{ Components } & \multicolumn{4}{c|}{ The components number, mass \%: } \\
\cline { 2 - 5 } & Control & 1 & 2 & 3 \\
\hline Portland cement & 28.3 & 26.3 & 23.7 & 27.0 \\
\hline High-silica sand & 56.4 & 52.5 & 49.4 & 52.0 \\
\hline Water & 15.3 & 20.5 & 24.1 & 16.8 \\
\hline Soluble water glass & - & 0.7 & 2.8 & 4.2 \\
\hline Number of thermal cycling at $\mathrm{t}=500^{\circ} \mathrm{C}$ & 4 & 11 & 29 & 20 \\
\hline
\end{tabular}

When added into the mineral wool solution, the influence of soluble water glass on its thermal resistance is changing. 
Refractory plastering on the base of soluble water glass binder with reinforcing additive could enhance thermal resistance properties six-fold if compared with the standard one [5]. In this respect the content of soluble water glass could be increased with the purpose of enhancing mortar thermal resistance. However, when introducing more than $20 \%$ of soluble water glass by volume (in relation to water volume), the mortar is losing its working life and setting instantly which is not acceptable.

In order to investigate the possible causes of increase in thermal stability of cement mortars in the presence of soluble water glass, the authors have carried out differential thermal gravimetric analysis (DTGA) of kinetics of chemical and physical-chemical processes. As the objects of DTGA the specimens with the following composition have been selected (table 5).

Table 5. Mortar compositions with added soluble water glass.

\begin{tabular}{|c|c|c|}
\hline Test number & Water / Cement ratio & Volume of soluble water glass, \% \\
\hline 1 & 0.28 & 0.1 \\
\hline 2 & 0.315 & 5.05 \\
\hline 3 & 0.35 & 0.1 \\
\hline 4 & 0.35 & 5.05 \\
\hline
\end{tabular}

The obtained thermograms of tested specimens allow revealing the following regularities: the DTGA-curves are characterized by three endothermic peaks; introduction of soluble water glass into the composition of cement compound materials has a significant impact on the composition and structure of cement stone. The thermograms of tested specimens exhibit the appearance of new peak at the temperatures ranging $675-695^{\circ} \mathrm{C}$ that points to formation of calcium hydro silicates giving additional thermal strength to cement stone. Thus, the higher the content of calcium hydro silicates in cement stones, the stronger their structure.

The authors implemented quantitative test of structure change for the researched specimens when heated. The results of analysis are given in table 2 . The mass loss was ranging from 16.98 to $19.24 \%$. The minimum mass loss was fixed for the specimen mixed on gauge water, water/cement ration accounted for 0.314 and $5.05 \%$ of soluble water glass.

The fig. 2 has shown the degree of thermal stability of physically and chemically bonded water and hydrate chemical entities at phase conversions of mortars within corresponding temperature range defined by the DTGA-curves. 


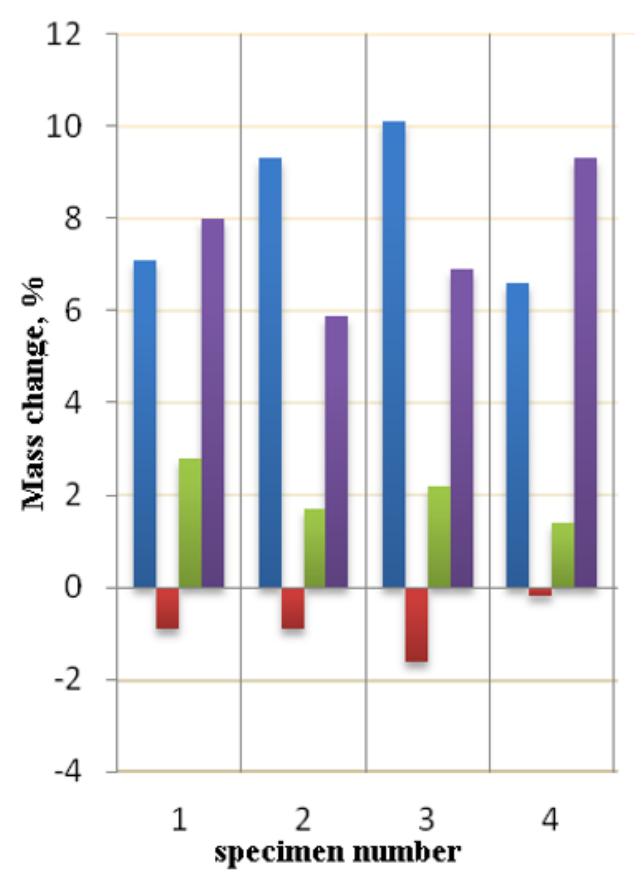

The removal of gravitational and physically bound water

The transition of silicon dioxide from beta- to alpha-modification

- Dehydrating hydrate of lime and removal of chemically bound water

\section{Dehydrating hydrated calcium \\ silicate of various base strength and calcspar}

Fig. 2. The degree of thermal stability of physically and chemically bonded water and hydrate chemical entities of mortar (specimen number correlates with the compositions given in the table 5).

\section{Conclusions}

The presented data provide some evidence that kinetic characteristic of cement hardening depend on introduction of soluble water glass and water/cement ratio. As the investigation results have showed, the best result had been registered when applying the concentration of soluble water glass $5.05 \%$ and water/cement ratio equal to 0.35 . According our opinion, the positive impact of phase conversions on kinetics changes could be related to formation of stronger chemical bonds. This is proved by the fact that the third (dehydration of calcium hydro silicates) and the fourth endoeffects (calc spar destruction) are characterized by the maximum enthalpy area and deeper peaks shifted towards elevated temperatures $[16,17]$.

The special attention is to be paid at the technology of production of refractory plaster mortar on the base of composite binders and fillers. The most efficient and cost-saving sequence is the following: glass sand, mineral wool fibers, Portland cement are mixed with approximately $50 \%$ of the required amount of water, then the remaining water is added into the mixture containing soluble water glass. The prepared mixture should be used within 1 hour $[18,19]$.

The implemented investigation enabled authors to come to conclusion that silicate additives significantly improve thermal-physical properties of cement composites at elevated temperatures. Silicate additives prevent rapid preheat of the specimens to a greater or lesser degree that improve stability of building structures in the event of fire [20]. 


\section{References}

1. A. Tarasova, Refractory binders and concretes on the base of soluble water glass Moscow. Stroiizdat 133 (1982)

2. K. Popov, M. Kaddo, Building materials and articles Moscow Higher Educational Institutions 367 (2001)

3. A. Komar, Building materials and articles Moscow Higher Educational Institutions 527 (1988)

4. I. Malyi, A. Vetoshkin, M. Akulova, O. Potemkina, Yu. Chshepochkina, V. Emelin, Patent of the RF, Raw mixture for aerated concrete (2011)

5. M. Akulova, O. Potemkina, V. Emelina, A. Kollerov, Privolzhsky Scient. J. 1 17-21 (2013)

6. M. Akulova, N. Belyakova, A. Kollerov, O. Potemkina, J Fire Safety 4 42-46 (2013)

7. S. Koksharov, A. Bazanov, S. Fedosov, M. Akulova, T. Slizneva, Eurasian chemico-tech. J. 174 327-33 (2015)

8. S. Koksharov, O. Meteleva, S. Fedosov, M. Akulova, Proceed. of the Scient.-Practical Conference Research and Development 491-501 (2017)

9. A. Smirnow, A. Petrow, A. Baranov, M. Akulova, Trade J. for the Autoclaved Aerated Concrete Industry 1 56-61 (2018)

10. M. Akulova, D. Phlegontov, A. Mochalov, O. Potemkina, Int. Conf. of Ind. Technologies and Engineering Shynkent 374-379 (2016)

11. S. Phedosov, M. Akulova, B. Isakulob, Zh. Tukashev, Proceed. of Int. Sci. Conference Almati $304-09$ (2013)

12. Y.Gao, B. He, M. Xiao, Z. Fang, K. Dai, J. Construction and building materials 165 548-59 (2018)

13. F. Brooks, Cement Composition for High Temperature Wells Chem. Abstr. 64038093 (1977)

14. H. Udagawa, I. Kobayashi, T. Ando, Cement Admixture for Decreasing Heat of Hydration, Japan Kokai Chem. Abstr. 223 (1980)

15. E. Ionescu, S. Teslaru, S. Enescu, Chem. Abstr. 964872 (1980)

16. K. Denki, Cement Additive Japan Kokai Chem. Abstr. 9121935 (1981)

17. T. Akasaka. H. Yamada, Hardened Cement Product with High Strength, Japan Kokai Chem. Abstr. 879 (1980)

18. T. Harmathy, Thermal properties of concrete at elevated temperature National Research Council Research paper n. 426211 (1986)

19. T. Harmathy, Effect of moisture on the fire endurance of building elements National Research Council Ottawa Canada 54 (1965)

20. T. Harmathy, Canadian J. of Civil Eng. 3 219-28 (1986) 